\title{
The degree of protection different ants (Hymenoptera: Formicidae) provide aphids (Hemiptera: Aphididae) against aphidophages
}

\author{
Tatiana A. NOVGORODOVA and Anton V. GAVRILYUK \\ Institute of Systematics and Ecology of Animals, Siberian Branch of the Russian Academy of Sciences, Frunze str. 11, \\ Novosibirsk, 630091, Russia; e-mail: tanovg@yandex.ru
}

Key words. Formicidae, Aphididae, ants, aphids, aphidophages, degree of protection, trophobiosis, behaviour

\begin{abstract}
Aphids play an important role in the life of many ant species supplying them with energy-rich carbohydrate food and in exchange receiving some degree of protection from natural enemies. This study focused on the degree of protection different ants provide myrmecophilous aphids (Hemiptera: Aphididae) in multispecies ant communities. Field investigations were carried out in steppe and forest plant associations in Siberia. The potential level of aggressiveness of six ant species (Formica rufa Linnaeus, F. pratensis Retzius, Lasius fuliginosus (Latreille), L. niger (Linnaeus), Camponotus saxatilis Ruzsky and Myrmica rubra Linnaeus) towards imagines and larvae of ladybirds and lacewings and larvae of hoverflies was tested in the laboratory. A comparative analysis of the occurrence of aphidophages in colonies of the aphid Chaitophorus populeti Panzer and of all aphid-symbionts tended by different ants in the study area has shown that the degree of protection of myrmecophilous aphids from natural enemies significantly differs among ants and is positively correlated with ant colony size. On the whole, the degree of protection of myrmecophilous aphids from aphidophages depends both on the potential level of aggressiveness of ants and their foraging strategy when collecting honeydew (degree of specialisation among honeydew collectors). As the dominant ants Formica s. str. were the most aggressive and provided aphids with the highest degree of protection, we suppose that these ants have the most important influence on the survival of the symbionts in multispecies ant communities whereas the other ants, which live in small colonies of about $10^{2}-10^{3}$ workers, appear at least partially to take advantage of the mutualistic relationships of the dominant ants.
\end{abstract}

\section{INTRODUCTION}

Trophobiotic interactions with various sap-feeding insects are widespread among ants (Hymenoptera: Formicidae) (Hölldobler \& Wilson, 1990; Delabie, 2001). Ants collect sugar-rich excretions of trophobionts (honeydew) and in exchange protect them from their natural enemies (e.g. Way, 1963; Vepsäläinen \& Savoläinen, 1994; Yao et al., 2000; Fischer et al., 2001). Ants are known to have trophobiotic relationships with insects of three orders: Hemiptera, including insects of three suborders: Sternorrhyncha (aphids, scale insects, white flies), Auchenorrhyncha (leafhoppers, planthoppers) (Delabie, 2001) and Heteroptera (true bugs) (Gibernau \& Dejean, 2001; Waldkircher et al., 2004), Lepidoptera (larvae of Lycaenidae, Riodinidae and Tortricidae) (Maschwitz et al., 1986; Pierce et al., 2002) and Hymenoptera (larvae of the sawfly Blasticotoma filiceti Klug) (Shcherbakov, 2006; Novgorodova \& Biryukova, 2011a). "Homopterans" (insects of the suborders Sternorrhyncha and Auchenorrhyncha) and aphids in particular, play an important role in the life of many ant species in supplying them with large amounts of energy-rich carbohydrate food. Survival of trophobionts is known to depend on ant attendance. For instance, the number of colonies of myrmecophilous aphids (tended by ants) is significantly higher close to ant nests (Schmutterer, 1956; Bradley \& Hinks, 1968). In addition, many studies have shown that colonies of myrmecophilous aphids tended by ants survive better than unattended ones (e.g. Addicott, 1978; Skinner \& Whit- taker, 1981; Bishop \& Bristow, 2003; Nagy et al., 2007). Furthermore, excluding ants from aphid colonies leads to the decline and extinction of aphid populations (Bradley \& Hinks, 1968; Tilles \& Wood, 1982; Karhu, 1998; Shingleton \& Foster, 2000; Novgorodova, 2005a). The presence of ants increases the fitness of aphids by decreasing the negative effect of aphidophages (Way, 1963; Tilles \& Wood, 1982; Fischer et al., 2001; Phillips \& Willis, 2005), increasing the feeding rates of aphids and speeding up their development (Banks \& Nixon, 1958; Flatt \& Weisser, 2000; Stadler et al., 2002). However, comparative analysis of the extinction rates of aphid colonies has shown that survival of myrmecophilous aphids depends on the species of ant tending them (Addicott, 1978; Bristow, 1984; Novgorodova, 2005a). This is likely to be explained mainly by the degree of protection ants provide aphids against natural enemies (predators and parasitoids), which are capable of decreasing the size or even eliminating aphid colonies unattended by ants. The effectiveness of the protection ants provide "Homopterans", including aphids, differs among tending ants (Buckley \& Gullan, 1991; Itioka \& Inoue, 1999; Katayama \& Suzuki, 2003). This suggests that the effect of different ants on the survival of aphids is unequal. However, the degree and reasons for these differences are unclear.

We suppose that the success of ant-tended sap-feeding insects is closely connected with the behaviour of ants collecting honeydew. The organization of honeydew collection significantly differs among ants of various 
species: from that of unspecialized foragers to "professional" specialization in which there is a clear division of at least two main tasks (honeydew collection and protection of aphid colonies) in groups of workers tending aphid colonies (Novgorodova \& Reznikova, 1996; Reznikova \& Novgorodova, 1998; Novgorodova, 2004, 2008). Furthermore, observation of ant behaviour in aphid colonies has shown that ants react differently towards adult and larval aphidophages. For instance, ants usually actively react to quickly moving aphidophages (mainly adult insects), including parasitic wasps, and drive them away or kill them, whereas they often pay no attention to the slowly moving larvae of various aphidophages: hoverflies and lacewings (Wellenstein, 1952; Tarbinskii et al., 1967; Marikovskii, 1979), larvae of the silver fly Leucopis sp. (Dlusskii, 1967). However, this behaviour is poorly recorded and only for certain ant species.

The comparative analysis of the behaviour of various members of multispecies ant communities towards natural enemies of their trophobiont-partners may help us to understand the role of different ants in the forming and maintaining of trophobiotic relationships with sap-feeding insects, particularly aphids. This study is one of the first on this topic and focuses on the degree of protection aphids receive from ants. The main aims of this study were to determine whether there are any differences in: (i) the occurrence of aphidophages in aphid colonies tended by different ants; (ii) the behaviour of different ants during their interaction with aphidophages and (iii) the behaviour of ants towards adult aphidophages and their larvae.

\section{MATERIAL AND METHODS}

\section{Sites investigated}

The investigations were carried out in June-August in 2003-2010 in Siberia in forest and steppe plant associations of three regions: in coniferous forests in the North-eastern Altai (north end of Lake Teletskoe, $51^{\circ} 48^{\prime} \mathrm{N}, 87^{\circ} 17^{\prime} \mathrm{E}$, alt. $434 \mathrm{~m}$ a.s.1., near Artybash, the Altai Republic; 2007-2010); in pine and aspen-birch-pine forests $\left(54^{\circ} 57^{\prime} \mathrm{N}, 83^{\circ} 06^{\prime} \mathrm{E}\right.$, alt. $200 \mathrm{~m}$ a.s.l., near Novosibirsk, the Novosibirsk region; 2003-2005) and mixed-grass-cereal steppes with aspen-birch groves in the Novosibirsk region $\left(53^{\circ} 44^{\prime} \mathrm{N}, 78^{\circ} 02^{\prime} \mathrm{E}\right.$, alt. $110 \mathrm{~m}$ a.s.l., near Karasuk; 2007-2009) and in the Kurgan region $\left(55^{\circ} 27^{\prime} \mathrm{N}\right.$, $65^{\circ} 20^{\prime} \mathrm{E}$, alt. $75 \mathrm{~m}$ a.s.1., near Kurgan; 2007-2008). Colonies of aphids were searched for 2-3 times during the summer alongside roads (in total, more than $120 \mathrm{~km}$ ) and at eight specific plots (in total, about $15 \mathrm{ha}$ ) located in different plant communities: 3 in aspen-birch-pine forests, 2 in pine forests near Novosibirsk, 2 in mixed-grass-cereal steppes with aspen-birch groves near Karasuk and 1 in coniferous forest near Artybash. The specific sites were characterized by similar structure in terms of the ant communities including dominant species with large protected territories (ants of Formica rufa group and Lasius fuliginosus (Latreille) in forest ant communities and Formica pratensis Retzius and $F$. sanguinea Latreille in steppe ant communities), subdominant and subordinate ants (Table 1). All the data obtained during the searches of the plants growing alongside roads and at the specific plots in the same plant community in the same region were pooled.
The degree to which different ants protected aphids from aphidophages

We searched trees, shrubs and grasses, including the roots of these plants growing along of our routes and at specific plots. For 1-2 min after detecting an aphid colony the behaviour of the insects on the plant was recorded and the presence or absence of aphidophages in or just near aphid colonies tended by ants noted. When aphidophages (including larvae of parasitoids in mummified aphids) were observed in an aphid colony and the ants collecting honeydew did not demonstrate any aggressive reactions towards them and when aphidophages were located just near an aphid colony (at a distance less than $7 \mathrm{~cm}$ ) and successfully attacked aphids despite the attending ants, the aphid colonies were classified as with aphidophages. Those aphid colonies categorized as without aphidophages include all cases when there were no aphidophages in aphid colonies and those when aphidophages were attacked (dropped from the plant or killed) by ants.

The aphid colonies that were not attended by ants were excluded from the data analysis because we didn't plan to compare the occurrence of aphidophages in colonies of myrmecophilous and non-myrmecophilous aphids in this paper. In addition, it is rather difficult to decide whether a colony is an unattended colony of myrmecophilous aphids or one left unattended by ants for some time when the ants transport the honeydew to their nests.

The occurrence of aphidophages in aphid colonies is the proportion of aphid colonies studied with aphidophages of those attended by ants of a certain species. The presence of aphidophages (even only one insect) that can freely attack aphids in an aphid colony tended by ants can be crucial for aphids and lead to their extinction sooner or later, so the numbers of aphidophages, aphids and ants were not taken into consideration in this study.

Aphids, ants and imagines of aphidophages from the aphid colonies investigated were collected and fixed in $70 \%$ alcohol. Larvae of predators and parasitoids (in mummified aphids) were reared in plastic boxes $(0.25$ and 0.501$)$ under laboratory conditions. In total, 3816 aphid colonies were examined. The trophobiotic interactions of 20 species of ants with aphids were recorded. The total number of aphid colonies tended by different ant species strongly depended on the abundance of ants in the area searched and intensity of their trophobiotic interactions with aphids (Table 1).

We analyzed the occurrence of aphidophages in colonies of the obligate myrmecophilous aphid Chaitophorus populeti Panzer (the percentage of aphid colonies with aphidophages) tended by different ants in Novosibirsk region. In order to assess the degree of protection of aphids by the ants in general we analyzed the occurrence of aphidophages in colonies of aphids tended by ants of different species (general symbionts). These aphids are a potential source of a basic resource for ants in multispecies ant communities. In each region the degree of protection of aphids from aphidophages was estimated only for the ant species that were recorded in more than 25 aphid colonies. As a result the degree of protection of aphids from aphidophages was analyzed for ants of only 19 ant species.

\section{Behaviour of ants tending aphids towards aphidophages}

In order to test the hypothesis that ants are more aggressive towards quickly moving imagines of aphidophages the behaviour of ants collecting honeydew towards aphidophagous insects ("mobile" imagines and "slowly moving" larvae) was investigated experimentally under laboratory conditions. We observed pairwise interactions between the ants (Formica rufa Linnaeus, $F$. pratensis, Lasius fuliginosus, L. niger Linnaeus, Camponotus 
TABLE 1. Ant species investigated. Values for the sizes of the ant colonies and types of territorial organization cited are based on data in the literature (Dobrzańska, 1966; Brian, 1983; Reznikova, 1983, 1999; Zakharov, 1991). Aphid colonies were examined in: pine forests (1) and aspen-birch-pine forests (2) in Novosibirsk region near Novosibirsk, mixed-grass-cereal steppes with aspenbirch groves near Karasuk - 3; mixed-grass-cereal steppes with aspen-birch groves in Kurgan region near Kurgan - 4; coniferous forests in North-eastern Altai near Artybash - 5.

\begin{tabular}{|c|c|c|c|c|c|c|c|c|c|}
\hline & \multirow{2}{*}{ Ant species } & \multirow{2}{*}{$\begin{array}{c}\text { Hierarchical } \\
\text { status }\end{array}$} & \multirow{2}{*}{ Foraging territory } & \multirow{2}{*}{ Colony size } & \multicolumn{5}{|c|}{ Aphid colonies examined } \\
\hline & & & & & 1 & 2 & 3 & 4 & 5 \\
\hline \multicolumn{10}{|c|}{ FoRMICINAE } \\
\hline 1 & Formica rufa Linnaeus & Dominant & Protected & $10^{5}-10^{6}$ & 178 & 0 & 94 & 37 & 0 \\
\hline 2 & F. aquilonia Yarrow & Dominant & Protected & $10^{5}-10^{6}$ & 0 & 57 & 0 & 0 & 67 \\
\hline 3 & F. polyctena Förster & Dominant & Protected & $10^{5}-10^{6}$ & 12 & 188 & 2 & 42 & 82 \\
\hline 4 & F. truncorum Fabricius & Codominant & Protected & $10^{4}-10^{5}$ & 100 & 0 & 0 & 0 & 41 \\
\hline 5 & F. pratensis Retzius & Dominant & Protected & $10^{4}-10^{5}$ & 18 & 143 & 311 & 70 & 0 \\
\hline 6 & $\begin{array}{l}\text { Formica (Raptiformica) sanguinea } \\
\text { Latreille }\end{array}$ & Codominant & Partially protected & $10^{3}-10^{4}$ & 10 & 23 & 30 & 2 & 0 \\
\hline 7 & $\begin{array}{l}\text { F. }(\text { Serviformica }) \text { glauca } \text { Ruzsky } \\
\text { (=F. cunicularia glauca } \text { Ruzsky) }\end{array}$ & Subdominant & Unprotected & $10^{2}-10^{3}$ & 8 & 40 & 41 & 37 & 0 \\
\hline 8 & F. (S.) fusca Linnaeus & Subdominant & Unprotected & $10^{2}-10^{3}$ & 29 & 6 & 33 & 42 & 29 \\
\hline 9 & F. (S.) candida F. Smith & Subdominant & Unprotected & $10^{2}-10^{3}$ & 0 & 0 & 0 & 0 & 40 \\
\hline 10 & F. (S.) lemani Bondroit & Subdominant & Unprotected & $10^{2}-10^{3}$ & 0 & 0 & 0 & 0 & 32 \\
\hline 11 & Camponotus saxatilis Ruzsky & Subdominant & Partially protected & $10^{2}-10^{3}$ & 17 & 59 & 0 & 34 & 3 \\
\hline 12 & C. herculeanus (Linnaeus) & Subdominant & Partially protected & $10^{2}-10^{3}$ & 34 & 0 & 47 & 1 & 0 \\
\hline 13 & Lasius fuliginosus (Latreille) & Codominant & Protected & $10^{5}-10^{6}$ & 98 & 77 & 138 & 0 & 38 \\
\hline 14 & L. niger (Linnaeus) & Subdominant & Partially protected & $10^{3}-10^{4}$ & 179 & 227 & 269 & 205 & 55 \\
\hline 15 & L. platythorax Seifert & Subdominant & Partially protected & $10^{3}-10^{4}$ & 61 & 11 & 0 & 0 & 4 \\
\hline 16 & L. alienus Förster & Subdominant & Partially protected & $10^{3}-10^{4}$ & 0 & 0 & 36 & 8 & 0 \\
\hline \multicolumn{10}{|c|}{ MYRMICINAE } \\
\hline 17 & Myrmica rubra Linnaeus & Subordinate & Unprotected & $10^{2}-10^{3}$ & 54 & 92 & 27 & 38 & 32 \\
\hline 18 & M. ruginodis Nylander & Subordinate & Unprotected & $10^{2}-10^{3}$ & 12 & 31 & 1 & 0 & 9 \\
\hline 19 & M. scabrinodis Nylander & Subordinate & Unprotected & $10^{2}-10^{3}$ & 0 & 0 & 10 & 0 & 0 \\
\hline 20 & Tetramorium caespitum (Linnaeus) & Subordinate & Unprotected & $10^{2}-10^{3}$ & 52 & 7 & 1 & 2 & 3 \\
\hline
\end{tabular}

saxatilis Ruzsky, Myrmica rubra Linnaeus) and aphid predators that were the most common and numerous in the insect communities investigated. As it was rather difficult to find a large number of imagines and larvae of aphidophages of the same species in the areas studied we used a mixture of species in some cases: ladybirds [imagines and larvae: Coccinella septempunctata Linnaeus and Harmonia axyridis (Pallas)], lacewings [imagines and larvae: Chrysopa perla Linnaeus and Chrysotropia ciliata (Wesmael)] and larvae of hoverflies [Syrphus ribesii (Linnaeus)]. The percentage of different species of aphidophages in the mixtures used in the experiments with the different species of ants was about $1: 1$. Insects were collected from the field two days before the experiment. Ants of each species studied were collected from the colonies of the obligate myrmecophilous aphid Symydobius oblongus Heyden and were kept in plastic boxes $(30 \times 30 \times 20 \mathrm{~cm})$. Aphidophagous insects were collected from plants in the same biotope and were kept in plastic boxes with plants infested with aphids. Experiments on ant-aphidophage pairwise interactions were carried out in plastic boxes $(14 \times 14 \times 5 \mathrm{~cm})$ with one ant per box and 30 replicates for each species of ant. An ant was placed into the box and allowed 5-10 min to adapt to the conditions and then aphidophages were placed into the box in sequence (larvae and imago of ladybirds, larvae and imago of lacewings, larvae of hoverflies), with about 10-15 min intervals between tests. In order to reduce the effect of differences in the size of the aphidophagous larvae on the behaviour of ants, the larvae of ladybirds, lacewings and hoverflies chosen for experiments were of the same length (about 12-14 mm). Preliminary observations in field have shown that the first reaction of ants towards natural enemies of aphids, independent of their group or species, usually determines whether aphidophages will have a chance to attack aphids or not. This is why the behaviour of insects was observed and recorded until their first contact but not for longer than 15 min. Eight patterns of ant behaviour were recorded: (1) avoidance - running away; (2) tolerance - neutral reaction (ant does not pay any attention to aphidophage); (3) investigation of the aphidophage using antennae; (4) "an alert pose" - standing still with mandibles slightly open and antennae slightly extended towards the aphidophage; (5) body jerking - usually repeated rapid forward-and-back jerking with open mandibles, without any contact with the irritant, (6) "hit-and-run attack" sudden attack on the aphidophage with open mandibles; (7) bite - short biting; (8) the "death grip" - a prolonged biting/stinging fight (ant seizes the aphidophage and does not lose its grip). Ants' reactions were divided into two groups according to the degree of aggressiveness (low and high, respectively): "nonaggressive" (1-4) and "aggressive" (5-8). If an ant demonstrated a range of reactions, quickly changing from one to another during its first contact with an aphidophage, only the most aggressive interaction was recorded. Plastic boxes were washed and treated with ethanol after each set of tests with each ant. Aphidophagous insects attacked by the ants (when ants demonstrated "hit-and-run attacks", bites and "death grip") or explored by them were used only once. Other insects (that did not have any direct contact with ants) could be used 1-3 times 
Ants

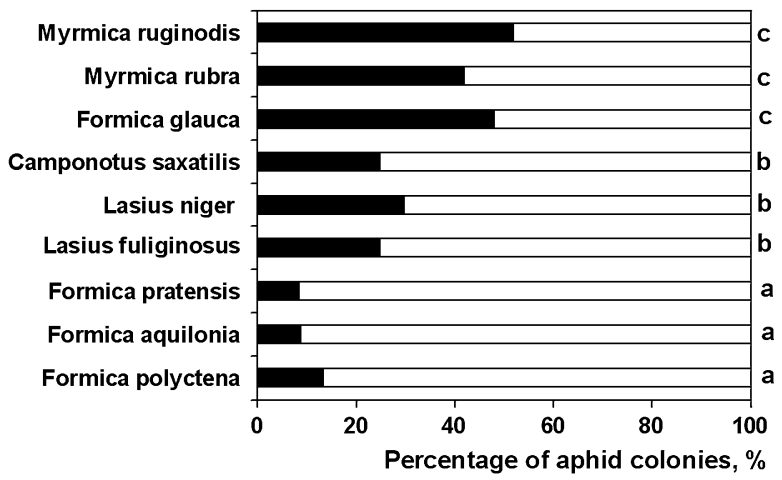

Ants

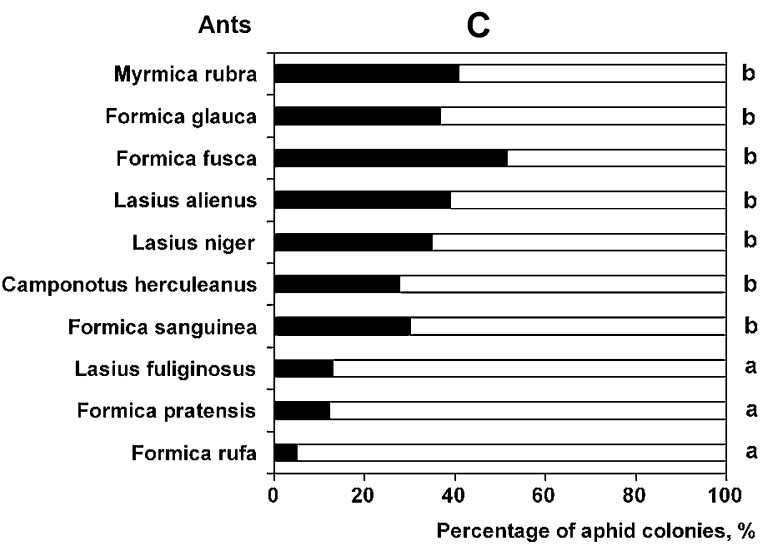

Ants

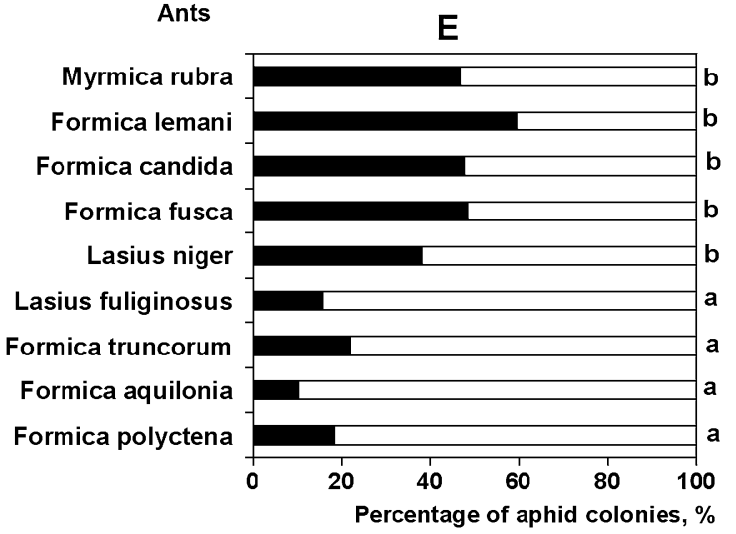

Ants

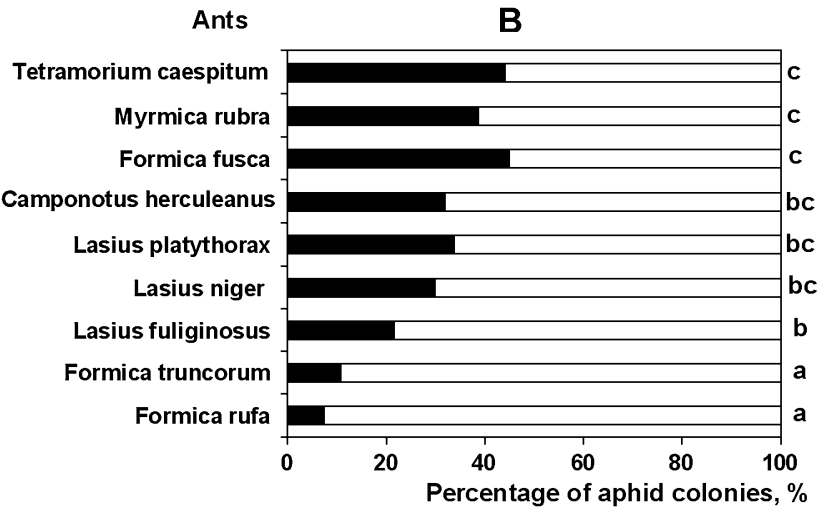

Ants
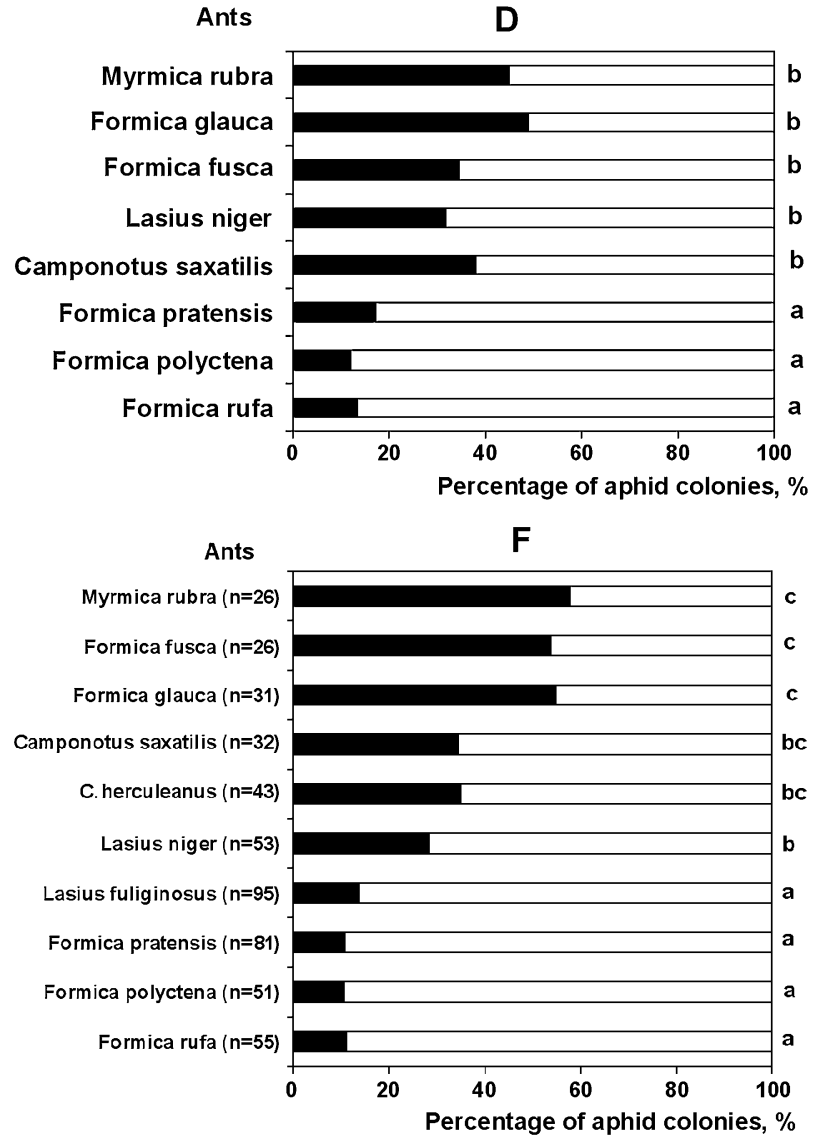

with aphidophages $\square$ without aphidophages

Fig. 1. The percentage of ant attended aphid colonies with aphidophages. A-E - The results for colonies of aphids tended by ants of different species in different regions. A - pine forests and B - aspen-birch-pine forests near Novosibirsk (the Novosibirsk region); $\mathrm{C}$ - mixed-grass-cereal steppes with aspen-birch groves near Karasuk (the Novosibirsk region); D - mixed-grass-cereal steppes with aspen-birch groves near Kurgan (the Kurgan region); E - coniferous forests near Artybash (the Altai Republic); F - the results for colonies of the aphid Chaitophorus populeti Panzer studied in the Novosibirsk region. The results marked with different letters are significantly different (Yates' corrected $\chi^{2}-$ test, $\left.\mathrm{p}<0.05\right)$ and those marked with the same letter are not significantly different $(\mathrm{p}>$ $0.05)$.

with intervals between tests of not less than 30 min. During this time they were kept in plastic boxes with plants infested with aphids. In total 150 observations of pairwise ant-aphidophage interactions were recorded for each species of ant.

In order to compare the degree of protection of aphid colonies by ants from the most common and numerous natural enemies of aphids in general (not only from aphidophages from a definite group or species) the results for all the aphidophages studied were pooled.

\section{Data analysis}

In order to estimate the degree of relationship between colony size and degree of protection of aphids by ants we estimated the Spearman's rank order correlation between the size class of ant colonies (maximum and minimum figures from Table 1 that reflect order of magnitude) and the percentage of aphid colonies with aphidophages. A Kruskal-Wallis nonparametric test was used to analyze the occurrence of aphidophages in aphid colonies attended by different ants. The percentage of aphid colonies 


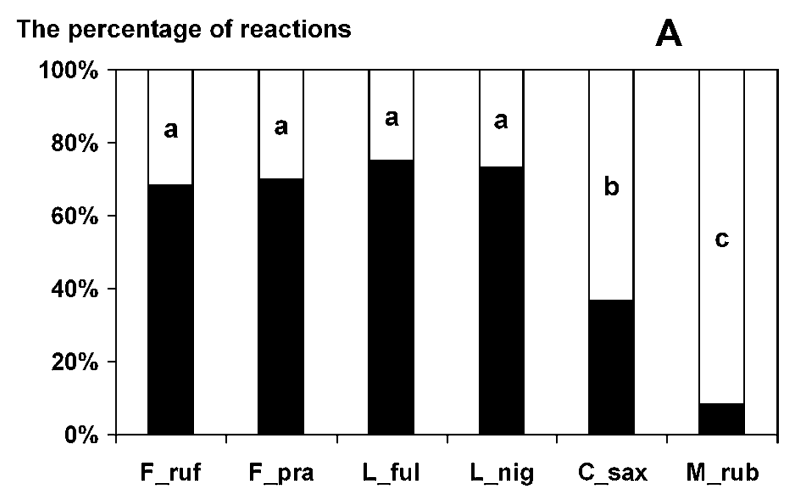

The percentage of reactions

B

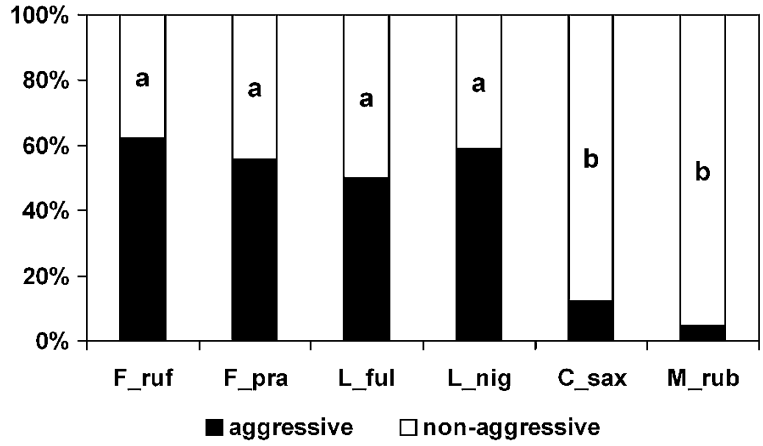

Fig. 2. The behaviour of honeydew collecting ants of the various species towards imagines (A) and larvae (B) of aphidophages during ant-aphidophage pairwise interactions. Ants: F_ruf - Formica rufa, F_pra - Formica pratensis, L_ful Lasius fuliginosus, L_nig - Lasius niger, C_sax - Camponotus saxatilis, M rub - Myrmica rubra. "Aggressive" reactions: body jerking, "hit-and-run attack", bite and "death grip". "Nonaggressive" reactions: avoidance, tolerance, investigation, "an alert pose". The results marked with different letters are significantly different (Yates' corrected $\chi^{2}$-test, $\mathrm{p}<0.001$ ).

with aphidophages among aphid colonies tended by different ants was analyzed by a Yates' corrected chi-square test. The ants' responses to potential predators of aphids (the percentage of "aggressive" and "non-aggressive" reactions) in laboratory experiments were also compared using Yates' corrected chisquare test. The results were analyzed using STATISTICA and Microsoft Excel software packages.

\section{RESULTS}

Colonies of 135 species of myrmecophilous aphids were found during this study. Only one specialized aphid species (tended by only one ant species) was found, the aphid Stomaphis quercus Linnaeus, which is tended only by Lasius fuliginosus in the areas studied. Thus, 99\% of the aphids tended by different ants provide them with a general resource. The most attractive aphids for the various ant species in the regions studied are: Symydobius oblongus and Chaitophorus populeti (13 ant species), Aphis fabae Scopoli (12), Cinara pinea Mordvilko and Glyphina betulae Linnaeus (9), Callipterinella tuberculata Heyden (8), Aphis plantaginis Goeze and Aphis farinosa Gmelin (7), Rhopalosiphum padi Linnaeus (6) and Metopeurum fuscoviride Stroyan (6). A smaller number of ant species tended other aphids.

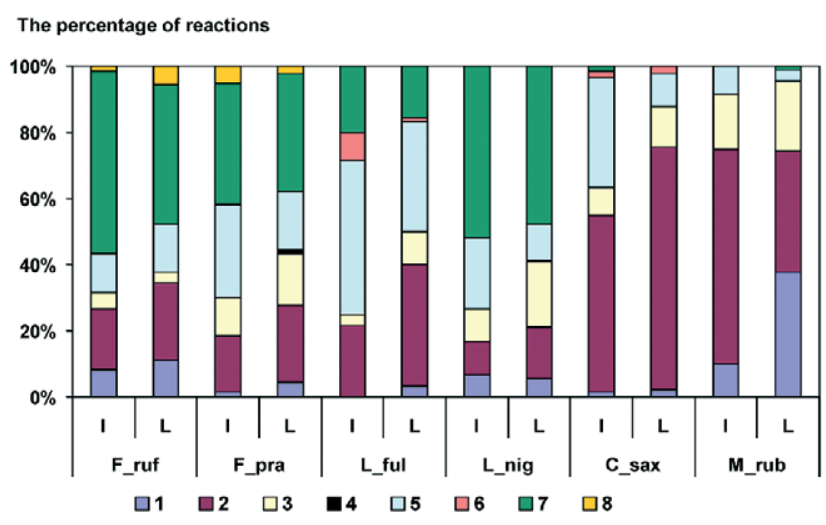

Fig. 3. The percentage of different behavioural reactions recorded in pairwise interactions between ants of different species and larvae (L) and imagines (I) of aphidophages. The abbreviations for the ant species are defined in Fig. 2. Behavioural reactions: 1 - avoidance, 2 - tolerance, 3 - investigation, 4 - "an alert pose" ("non-aggressive"); 5 - body jerking, 6 "hit-and-run attack", 7 - bite, 8 - the "death grip" ("aggressive").

One hundred and five species of aphidophages belonging to 12 families and 5 orders were identified in the aphid colonies: Hymenoptera - Aphidiidae (28 species), Aphelinidae (2) and Sphecidae (3); both larvae and imagines of Coccinellidae (Coleoptera) - 18 species; Diptera - Syrphidae (29 species), Cecidomyiidae (3) and Chamaemyiidae (1); Neuroptera - Chrysopidae (9), Raphidiidae (2) and Hemerobiidae (3); and bugs (Heteroptera) - Nabidae (4), Anthocoridae (2) and Reduviidae (1). The most common and numerous aphidophages in the insect communities studied belonged to Syrphidae, Coccinellidae, Chrysopidae and Aphidiidae.

\section{The degree to which different ants protect aphids from aphidophages}

Analysis of the occurrence of aphidophages in aphid colonies of Chaitophorus populeti tended by different ants in the Novosibirsk region revealed that the percentage of aphid colonies with aphidophages varies considerably (Kruskal-Wallis test: $\chi^{2}=73.245$, df $=9, p<$ 0.0001). The lowest occurrence of aphidophages is typical of aphid colonies tended by the obligate dominant ants Formica s. str. (F. rufa, F. polyctena Förster, F. pratensis) and L. fuliginosus (Fig. 1). The highest occurrence of aphidophages was recorded in aphid colonies tended by the ants Myrmica rubra and Formica of the subgenus Serviformica $[F$. (S.) fusca Linnaeus, $F$. (S.) glauca Ruzsky]. The ants Camponotus saxatilis, C. herculeanus (Linnaeus) and Lasius niger occupy an intermediate position. However, whereas the percentage of aphid colonies of Chaitophorus populeti tended by L. niger with aphidophages differed significantly from those tended by Myrmica rubra, Formica (Serviformica) glauca and F. (S.) fusca, there were no significant differences between the percentage of those attended by Camponotus and both $L$. niger and Myrmica rubra and ants of the subgenus Serviformica. 

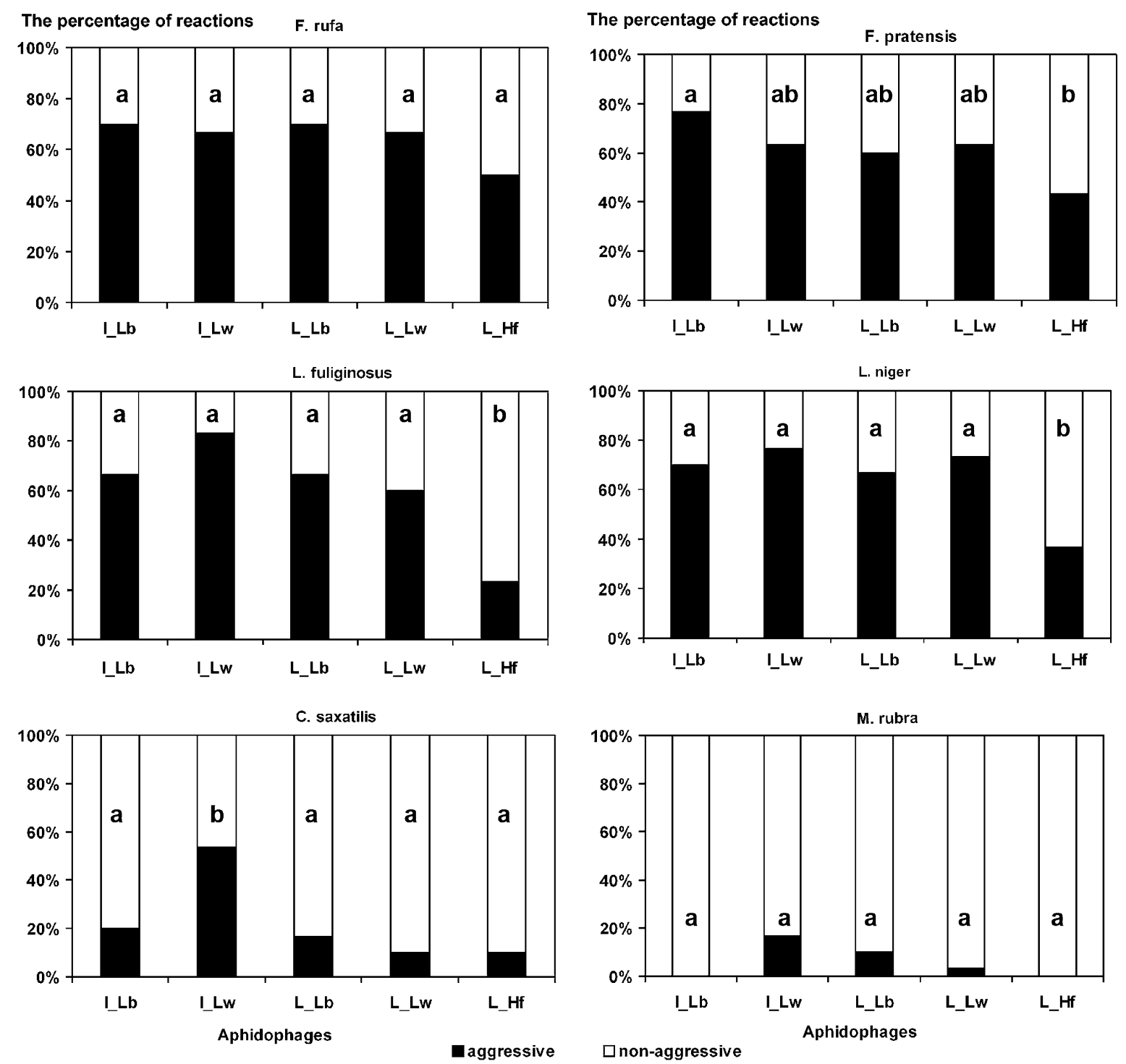

Fig. 4. The behaviour of honeydew collectors of various species of ants towards imagines (I) and larvae (L) of aphidophages (Hf hoverflies, Lb - ladybirds, Lw - lacewings) during ant-aphidophage pairwise interactions. "Aggressive" reactions: body jerking, "hit-and-run attack", bite and "death grip". "Non-aggressive" reactions: avoidance, tolerance, investigation, "an alert pose". The results marked with different letters are significantly different (Yates' corrected $\chi^{2}$-test, $p<0.05$ ).

A similar tendency was revealed by the analysis of the results for the ant species tending general aphidsymbionts (aphid species tended by different ants). The percentage of aphid colonies attended by different ants containing aphidophages varies considerably in all the regions studied [Kruskal-Wallis test: North-eastern Altai near Artybash $-\chi^{2}=52.107, \mathrm{df}=8, \mathrm{p}<0.0001$ (coniferous forests); Kurgan region near Kurgan $-\chi^{2}=40.322$, $\mathrm{df}=7, \mathrm{p}<0.0001$ (mixed-grass-cereal steppes with aspen-birch groves); Novosibirsk region near Karasuk $\chi^{2}=96.081$, df $=9, \mathrm{p}<0.0001$ (mixed-grass-cereal steppes with aspen-birch groves) and near Novosibirsk $\chi^{2}=70.999, \mathrm{df}=8, \mathrm{p}<0.0001$ (pine forest), $\chi^{2}=83.475$, $\mathrm{df}=8, \mathrm{p}<0.0001$ (aspen-birch pine forest)].

Based on the percentage of aphid colonies with aphidophages the ants can be divided into two or three groups in all the regions studied (Fig. 1). The highest occurrence of aphidophages in all cases was recorded in aphid colonies tended by the ants Myrmica, Formica (Serviformica) $[F$. (S). glauca, F. (S.) fusca, F. (S.) candida, F. (S.) lemani] and Tetramorium caespitum (Linnaeus). The lowest occurrence of aphidophages is typical of aphid colonies tended by the obligate dominant ants Formica s. str. ( $F$. rufa, $F$. aquilonia Yarrow, $F$. polyctena, $F$. pratensis, $F$. truncorum Fabricius). In three regions (Novosibirsk region near Karasuk, Kurgan region near Kurgan, Northeastern Altai near Artybash) the results for L. fuliginosus do not differ from those for Formica s. str. However in forest communities in Novosibirsk region (near Novosibirsk) the percentage of aphid colonies with aphidophages was significantly higher for L. fuliginosus than for Formica s. str. (Fig. 1). In aspen-birch-pine forests in this region L. fuliginosus occupies an intermediate position together with the ants $L$. niger and $C$. saxatilis. For pine forests the results for L. niger, L. platythorax Seifert and 
C. herculeanus do not differ from L. fuliginosus, Formica (S.) fusca, M. rubra and T. caespitum.

On the whole, the results for Camponotus saxatilis, $C$. herculeanus, Lasius niger and L. platythorax seem to be the most variable. These ants may occupy both an intermediate and the lowest position in terms of the degree of protection they provide aphids.

The percentage of aphid colonies with aphidophages was correlated with the size of the ant colonies in all regions. Results obtained using minimum and maximum sizes of ant colonies (from Table 1) are similar (Northeastern Altai near Artybash - Rs $=-0.944, \mathrm{n}=9, \mathrm{p}=$ 0.0001; Novosibirsk region near Novosibirsk - Rs = $-0.7891, \mathrm{n}=9, \mathrm{p}=0.012$ (aspen-birch-pine forests) and Rs $=-0.8433, \mathrm{n}=9, \mathrm{p}=0.004$ (pine forest); near Karasuk $-\mathrm{Rs}=-0.756, \mathrm{n}=10, \mathrm{p}=0.011$; Kurgan region near Kurgan $-\mathrm{Rs}=-0.7417, \mathrm{n}=8, \mathrm{p}=0.036$ ).

\section{Behaviour of ants attending aphids towards aphidophages (laboratory experiment)}

The comparative analysis of the reactions of ants to the most common and numerous aphid predators in the insect communities studied indicates that the ants differ in their behaviour towards aphidophages. Most "aggressive" reactions were recorded for the dominant ants Formica s. str. (F. rufa, F. pratensis) and L. fuliginosus and subdominant ants L. niger (Fig. 2). Bites usually predominated over other "aggressive" reactions in these ants, with the only exception L. fuliginous, which jerks its body more often (Fig. 3). The ants of these four species actively attacked both the adults and larvae of aphidophages (Figs 2, 4). The lowest number of "aggressive" reactions towards natural enemies of aphids was recorded for the subordinate ant M. rubra (Fig. 2). These ants are rarely "aggressive" towards adults $(8.3 \%$ - body jerking) and larvae (3.3\% - body jerking; $1.1 \%$ - bites) of aphidophages (Fig. 3). The subdominant ant C. saxatilis occupies an intermediate position among the ants studied. It is mostly tolerant of aphidophages (Fig. 3) and its "aggressive" reactions consist mainly of body jerking.

Besides, two species of ants, L. fuliginosus and C. saxatilis, show significant differences in their reaction towards aphidophages of different categories (imagines and larvae $)\left(\chi_{\text {real/critical }}^{2}=8.36 / 3.84, \mathrm{p}=0.0038\right.$ and $\chi_{\text {real/critical }}^{2}=$ $11.15 / 3.84, \mathrm{p}=0.0008$, respectively). These ants were more aggressive towards adult aphidophages (Fig. 2).

Detailed analysis of the ants' reactions to the different development stages of the most common and numerous aphid predators indicates that the ants Formica s. str. are more or less equally aggressive towards all the aphidophages tested (Fig. 4). Larvae of hoverflies induced fewer aggressive reactions from these ants, however significant differences in the behaviour of ants were revealed only for $F$. pratensis in comparison with their reactions to imagines of ladybirds. Ants of both species of Lasius were significantly less aggressive towards larvae of hoverflies (Fig. 4). C. saxatilis was the most aggressive towards imagines of lacewings. As for M. rubra ants, there were no significant differences in their reactions towards different aphidophages.

\section{DISCUSSION}

Ants are social insects that live in colonies consisting of a few up to several millions of individuals and exhibit various foraging and territorial behaviour (Beckers et al., 1989; Hölldobler \& Wilson, 1990). Protection of food resources from competitors is one of the key features of the life of ants that allows them to control and maintain a stable resource base and therefore obtain a sufficient quantity of food for survival and increasing their colony size. This primarily concerns long-term renewable sources of carbohydrate food such as trophobionts (e.g. aphid colonies), because honeydew excreted by sapfeeding insects is an important energy resource for various ant species (Hölldobler \& Wilson, 1990; Delabie, 2001) especially those living in large colonies of more than ten thousand individuals (Oliver et al., 2008). Increase in ant colony size is known to be accompanied by an increase in territorial organization (defence of territories for foraging) and foraging behaviour (the choice of foraging strategy and division of labour) (Reznikova, 1983; Beckers et al., 1989; Anderson \& McShea, 2001). The highest level of division of labour is typical of large ant colonies (Mailleux et al., 2003; Thomas \& Elgar, 2003). These results are consistent with the data on the behaviour of ants tending aphids. Ants exhibit different types of honeydew collection (Novgorodova \& Reznikova, 1996; Novgorodova, 2007, 2008). The most complex "professional" specialisation, with clear division of a number of tasks (honeydew collection by "shepherds", protection by "guards", transportation by "transporters" and searching for new aphid colonies by "scouts") occurs only in highly social ants of the genus Formica s. str. that live in colonies of about $10^{5}-10^{6}$ workers and forage over vast protected territories (Reznikova \& Novgorodova, 1998; Novgorodova, 2008). The results presented indicate that the increase in the complexity of the behaviour of the ants with increase in ant colony size is reflected in the degree of protection they provide aphids: the percentage of aphid colonies with aphidophages decreases with increase in the size of the colony of ants tending the aphids.

The highest occurrence of aphidophages was recorded in aphid colonies tended by ants [Myrmica, Tetramorium and Formica (Serviformica)] from small colonies (usually less than two thousand workers). A representative of this group of ants, Myrmica rubra, was the least aggressive towards aphidophages in the laboratory experiment. In $F$. (Serviformica) glauca $[=F$. (S.) cunicularia glauca Ruzsky] and $M$. rubra there is no specialization among the ants for collecting honeydew (Novgorodova, 2003; Panteleeva, 2004). Their colonies consist of unspecialised foragers that both collect and transport honeydew and as a consequence aphid colonies are often left unattended and unprotected from both other ants and natural enemies. Subordinate ants (Myrmica and Tetramorium) do not protect the territory they use for foraging. The other ants (Formica of the subgenus Serviformica) are subdominant. When the size of their colonies exceeds two-three thousand workers, these ants may protect the area they use for 
foraging close to their nest (Reznikova, 1983) and exhibit a partial division of tasks or some specialization among honeydew collectors (Novgorodova, 2003). However, the dominant ants, Formica s. str., strictly control the colony sizes of these ants by reducing the number of their workers (Reznikova, 1983, 1999).

An intermediate position in the list of increasing degree of protection of aphids by ants is occupied mainly by subdominant ants that live in colonies of about several thousand individuals (Lasius and Camponotus) and have small territories for foraging that are partially protected by the ants (usually only the area close to their nest) and also in some cases by dominant ants such as Lasius fuliginosus. Despite the fact that the ant L. niger was more aggressive towards aphidophages in pairwise interactions than the ant Camponotus saxatilis, L. niger did not provide its symbionts with higher degree of protection than ants of the genus Camponotus. This seems to be because unspecialized foragers of $L$. niger exhibit less complex behaviour in aphid colonies (Novgorodova, 2005b). Therefore, aphid colonies tended by this ant may often be left unattended when ants transport honeydew back to their nest, whereas Camponotus exhibits a partial division of tasks, with a few ants "on duty" for almost all the time in aphid colonies protecting the aphids from competitors, including aphidophages (Novgorodova \& Reznikova, 1996).

The lowest occurrence of aphidophages was recorded in aphid colonies tended by Formica s. str. that lives in large colonies $\left(10^{4}-10^{6}\right.$ individuals). All the ants in this group dominate in multispecies ant communities, control vast protected territories for foraging and exhibit the most complex behaviour (Hölldobler \& Wilson, 1990; Zakharov, 1991), including that of the foragers in aphid colonies that show the highest degree of specialization with a clear division of labour in a number of tasks (at least honeydew collection and protection of trophobionts) that allows these ants to increase their trophobiotic effectiveness (Reznikova \& Novgorodova, 1998; Novgorodova, 2005a, 2008; Novgorodova \& Biryukova, 2011b).

Based on the size of the ant colonies (about $10^{5}-10^{6}$ workers) and territorial behaviour [division of the area used for foraging between particular, permanent groups of workers (Dobrzańska, 1966)] the ant L. fuliginosus is closer to Formica s. str. than to any of the other ants studied. However, the degree of protection L. fuliginosus provides aphids against natural enemies is sometimes less than that provided by Formica s. str. and similar to that of Camponotus and L. niger. This seems to be because $L$. fuliginosus has a simpler way of collecting honeydew than ants of Formica s. str. Groups of workers of $L$. fuliginosus tending separate aphid colonies consist of unspecialized foragers that both collect and transport honeydew (Novgorodova, 2005b). Thus, these ants protect their trophobiont-partners only when present in the aphid colony. However unspecialized foragers of $L$. fuliginosus constantly change each other in aphid colony and rather rarely leave aphids unattended. Overall, the percentage of the aphid colonies tended by dominant ants with large protected forage territories (Formica s. str. and L. fuliginosus) with aphidophages is about 1.5-3.5 times lower than that for the ants Lasius and Camponotus, with partially protected territories and about 4-6 times lower than that for the ants from small colonies with non-protected foraging sites.

In the laboratory experiments the ants were slightly more aggressive towards "mobile" adult aphidophages (ladybirds and lacewings) than the more "slowly moving" larvae (ladybirds, lacewings and hoverflies). This is consistent with observations made in nature by other authors (Wellenstein, 1952; Dlusskii, 1967; Tarbinskii et al., 1967; Marikovskii, 1979). However, significant differences in the ants' reaction were revealed only for two species of ant, L. fuliginosus and C. saxatilis, in their interaction with imagines and larvae of aphidophages in general. Detailed analysis has shown that in case of $L$. fuliginosus differences in the ants' reaction towards imagines and larvae of aphidophages are due to the fact that ants were significantly rarely aggressive towards hoverfly larvae, whereas there were no significant differences between the ants in their reactions to other insects (imagines and larvae of ladybirds or lacewings). In contrast, $C$. saxatilis was rather tolerant of aphidophages including the larvae of all the groups tested and imagines of ladybirds. The only exception was the imagines of lacewings. Thus, the results of the laboratory experiments reflect the different potential levels of aggressiveness of the ants studied. Formica s. str. was the most aggressive and actively attacked aphidophages of any type. Lasius fuliginosus and L. niger were highly aggressive (more than $40 \%$ ) towards all groups of aphidophages tested except hoverfly larvae. Camponotus saxatilis was less aggressive and mostly protects aphids from the imagines of lacewings. Myrmica rubra barely protects its aphid symbionts from natural enemies.

The behaviour of ants towards aphidophages seems to depend on both the mobility and other peculiarities of predators: size, shape or even some mechanisms used by predators to evade ant attack while they feed on aphids. One of possible mechanisms used by aphidophages to decrease an ants' aggressiveness before contact is their ability to produce or acquire a mixture of cuticular hydrocarbons (CHCs) similar to that of the ants or aphids (Hölldobler \& Wilson, 1990; Lohman et al., 2006). The low level of aggressiveness towards the larvae of the hoverfly Syrphus ribesii seems to be due to their moving more slowly than the imagines and larvae of the other insects tested and the similarity of their CHCs profile to that of aphids (Lohman et al., 2006). Nevertheless these mechanisms do not prevent larvae of $S$. ribesii being attacked by the most aggressive and highly social Formica s. str. (F. rufa and F. pratensis). These ants are extremely good at identifying an enemy.

On the whole, the degree of protection ants provide myrmecophilous aphids from aphidophages depends on the level of aggressiveness of the ants and their foraging strategy, which is closely connected with ant colony size. Thus, the degree of protection ants of different species 
provide their general aphid-symbionts differ significantly depending on their level of social organization, territorial behaviour and type of honeydew collection (degree of specialization among honeydew collectors). The dominant Formica s. str., which have large colonies and protect vast territories for foraging, exhibit the most complex behaviour and level of specialization for collecting honeydew and provide aphids with the highest degree of protection. This study included all the myrmecophilous aphids tended by the different species of ants in the study area (general resource base for all members of multispecies ant community). The dominant ants seem to have the most important influence on the survival and population increase of trophobionts in multispecies ant communities. The other ants (subordinate species living in small colonies of about $10^{2}-10^{3}$ workers) appear to use, at least partially, the mutualistic relationships of the dominant ants. The role of subdominant ants that are less aggressive in protecting their territories and resources requires further study. The effectiveness of the various behavioural strategies of the aphidophages and the mechanisms they use to decrease or evade ants' aggressiveness also require further detailed study.

ACKNOWLEDGEMENTS. We would like to thank the following specialists for identifying the aphidophages: V.V. Dubatolov (Neuroptera), V.S. Sorokina (Syrphidae), A.S. Ukrainskii (Coccinellidae), E.M. Davidyan (Aphidiidae and Aphelinidae), V.A. Balakhonova (Heteroptera). For valuable comments on and interest in this study we are indebted to V. Markó. We are grateful to anonymous reviewers for their valuable comments on the manuscript. We would also like to thank J. Cooter (Oxford University Museum of Natural History, Oxford, UK) for improving and checking the English of this manuscript. This study was supported in part by the Russian Foundation of Basic Research (No 09-04-00152) and Presidium of Russian Academy of Sciences.

\section{REFERENCES}

AdDicotт J.F. 1978: Competition for mutualists: aphids and ants. Can. J. Zool. 56: 2093-2096.

Anderson C. \& McShea D.W. 2001: Individual versus social complexity, with particular reference to ant colonies. Biol. Rev. 76: 211-237.

BANKS C.J. \& NixON H.L. 1958: Effects of the ant, Lasius niger (L.), on the feeding and excretion of the bean aphid, Aphis fabae Scop. J. Exp. Biol. 35: 703-711.

Beckers R., Goss S., Deneubourg J.L. \& Pasteels J.M. 1989: Colony size, communication and ant foraging strategy. Psyche 96: 239-256.

Bishop D.B. \& BRistow C.M. 2003: Effects of the presence of the Allegheny mound ant (Hymenoptera: Formicidae) in providing enemy-free space to myrmecophilous aphid and soft scale populations. Ann. Entomol. Soc. Am. 96: 202-210.

Bradley G.A. \& Hinks J.D. 1968: Ants, aphids and jack pine in Manitoba. Can. Entomol. 100: 40-50.

Brian M.V. 1983: Social Insect Ecology and Behavioural Biology. Chapman \& Hall, London, $377 \mathrm{pp}$.

Bristow C.M. 1984: Differential benefits from ant attendance to two species of Homoptera on New York ironweed. J. Anim. Ecol. 53: 715-726.
Buckley R. \& Gullan P. 1991: More aggressive ant species (Hymenoptera: Formicidae) provide better protection for soft scales and mealybugs. Biotropica 23: 282-286.

Delabie J.H.C. 2001: Trophobiosis between Formicidae and Hemiptera (Sternorrhyncha and Auchenorrhyncha): an overview. Neotrop. Entomol. 30: 501-516.

Duusskil G.M. 1967: Ants of Genus Formica. Nauka, Moscow, 236 pp. [in Russian].

DoBRZAŃSKA J. 1966: The control of the territory by Lasius fuliginosus Latr. Acta Biol. Exp. 26: 193-213.

Fischer M.K., Hoffman K.H. \& VöLKL W. 2001: Competition for mutualists in an ant-homopteran interaction mediated by hierarchies of ant attendance. Oikos 92: 531-541.

Flatt T. \& Weisser W.W. 2000: The effects of mutualistic ants on aphid life history traits. Ecology 81: 3522-3529.

Gibernau M. \& DeJeAn A. 2001: Ant protection of a Heteropteran trophobiont against a parasitoid wasp. Oecologia 126: 53-57.

Hölldobler B. \& Wilson E.O. 1990: The Ants. Springer, Berlin, $732 \mathrm{pp}$.

Itioka T. \& InOue T. 1999: The alternation of mutualistic ant species affects the population growth of their trophobiont mealybug. Ecography 22: 169-177.

KARHU K.J. 1998: Effects of ant exclusion during outbreaks of a defoliator and a sap-sucker on birch. Ecol. Entomol. 23: 185-194.

Katayama N. \& Suzuki N. 2003: Bodyguard effects for aphids of Aphis craccivora Koch (Homoptera: Aphididae) as related to the activity of two ant species, Tetramorium caespitum Linnaeus (Hymenoptera: Formicidae) and Lasius niger L. (Hymenoptera: Formicidae). Appl. Entomol. Zool. 38: 427-433.

Lohman D.J., Liao Q. \& Pierce N.E. 2006: Convergence of chemical mimicry in a guild of aphid predators. Ecol. Entomol. 31: 41-51.

Mailleux A.-C., Deneubourg J.-L. \& Detrain C. 2003: How does colony growth influence communication in ants? Insectes Soc. 50: 24-31.

Marikovski P.I. 1979: Ants of Deserts of Semirechya. Nauka, Alma-Ata, 264 pp. [in Russian].

Maschwitz U., Dumpert K. \& Tuck K.R. 1986. Ants feeding on anal exudate from tortricid larvae: a new type of trophobiosis. J. Nat. Hist. 20: 1041-1050.

Nagy C., Markó V. \& Cross J. 2007: Effects of exclusion or supplementary honey feeding on the common black ant, Lasius niger (L.), on aphid populations and natural enemies on apple. IOBC/WPRS Bull. 30: 43-50.

Novgorodova T.A. 2003: Variety of behavioural models in the ant Formica cunicularia glauca in case of trophobiosis. Usp. Sovrem. Biol. 123: 229-233 [in Russian, English abstr.].

Novgorodova T.A 2004: The symbiotic relationships between ants and aphids. Zh. Obsch. Biol. 65: 152-165 [in Russian, English abstr.].

Novgorodova T.A. 2005a: Investments of the members of a multispecies ant association to the numerical potential of aphids as their common symbionts. Dokl. Biol. Sci. 401: 150-151.

Novgorodova T.A. 2005b: Peculiarities of mutual relations between aphids of two ant species of the genus Lasius (Formicinae). Usp. Sovrem. Biol. 125: 199-205 [in Russian, English abstr.].

Novgorodova T.A. 2007: The specialization in groups of ants tending aphid colonies (Hymenoptera: Formicidae; Homoptera: Aphididae). Myrmecol. News 10: 115. 
Novgorodova T.A. 2008: The specialization in ant working groups involved in trophobiosis with aphids. Zh. Obsch. Biol. 69: 293-302 [in Russian, English abstr.].

Novgorodova T.A. \& Biryukova O.B. 2011a: Some ethological aspects of the trophobiotic interrelations between ants (Hymenoptera: Formicidae) and larvae of the sawfly Blasticotoma filiceti (Hymenoptera: Blasticotomidae). Eur. J. Entomol. 108: 47-52.

Novgorodova T.A. \& Biryukova O.B. 2011b: Behavior of red wood ants (Hymenoptera, Formicidae) during interaction with different symbiont partners. Entomol. Rev. 91: 231-240.

Novgorodova T.A. \& Reznikova Zh.I. 1996: Ecological aspects of interaction between ants and aphids in the forest park zone of the Novosibirsk Scientific Centre. Siber. J. Ecol. (3-4): 239-245 [in Russian, English abstr.].

Oliver T.H., Leather S.R. \& CoOK J.M. 2008: Macroevolutionary patterns in the origin of mutualisms involving ants. $J$. Evol. Biol. 21: 1597-1608.

Panteleeva S.N. 2004: Interaction of Ants and Springtails as Hunters and Mass Prey. PhD thesis, Institute of Systematics and Ecology of Animals, Novosibirsk, 120 pp. [in Russian].

Phillips I.D. \& Willis C.K.R. 2005: Defensive behavior of ants in a mutualistic relationship with aphids. Behav. Ecol. Sociobiol. 59: 321-325.

Pierce N.E., Braby M.F., Heath A., Lohman D.J., Mathew J., Rand D.B. \& Travassos M.A. 2002: The ecology and evolution of ant association in the Lycaenidae (Lepidoptera). Annu. Rev. Entomol. 47: 733-771.

ReZnikova Zh.I. 1983: Interspecies Inter-relations in Ants. Nauka, Novosibirsk, 283 pp. [in Russian].

ReznIKova ZH.I. 1999: Ethological mechanisms of population density control in coadaptive complexes of ants. Russ. J. Ecol. 30: 187-192.

Reznikova Zh.I. \& Novgorodova T.A. 1998: Division of labour and exchange of information within ant settlement. Usp. Sovrem. Biol. 118: 345-357 [in Russian, English abstr.].

Schmutterer H. 1956: Saugschäden an Eichen und Buchen durch Lachniden in Abhängigkeit von Ameisen-Trophobiose. Z. Angew. Entomol. 39: 178-185.
Shingleton A.W. \& Foster W.A. 2000: Ant-tending influences soldier production in a social aphid. Proc. R. Soc. (B) 267: 1863-1868.

SkinNer G.J. \& WitTAKER J.B. 1981: An experimental investigation of interrelationships between the wood ant (Formica rufa) and some tree-canopy herbivores. J. Anim. Ecol. 50: 313-326.

Stadler B., Dixon A.F.G. \& Kindlmann P. 2002: Relative fitness of aphids: effects of plant quality and ants. Ecol. Lett. 5: 216-222.

Tarbinski Yu.S., Pack L.V. \& IBraimova K.I. 1967: Food relationships of ants, aphids and hoverflies in fruit forests of Kyrgyzstan. Zool. J. 46: 1063-1068.

Thomas M.L. \& Elgar M.A. 2003: Colony size affects division of labour in the ponerine ant Rhytidoponera metallica. Naturwissenschaften 90: 88-92.

Tilles D.A. \& Woods D.L. 1982: The influence of the carpenter ant (Camponotus modoc) (Hymenoptera: Formicidae) attendance on the development and survival of aphids (Cinara spp.) (Homoptera: Aphididae) in a giant sequoia forest. Can. Entomol. 114: 1133-1142.

Vepsäläinen K. \& Savolainen R. 1994: Ant-aphid interaction and territorial dynamics of wood ants. Memor. Zool. 48: 251-259.

WaldKircher G., Webb M.D. \& Maschwitz U. 2004: Description of a new shieldbug (Heteroptera: Plataspidae) and its close association with a species of ant (Hymenoptera, Formicidae) in Southeast Asia. Tijdschr. Entomol. 147: 21-28.

WAY M.J. 1963: Mutualism between ants and honeydew producing Homoptera. Annu. Rev. Entomol. 8: 307-344.

WeLLENSTEIN G. 1952: Zur Ernährungsbiologie der Roten Waldameise (F. rufa L.). Z. Pflanzenkr. 59: 430-451.

Yao I., Shibao H. \& Aкimato S. 2000: Costs and benefits of ant attendance to the drepanosiphid aphid Tuberculatus quercicola. Oikos 89: 3-10.

ZAKHAROv A.A. 1991: The Organization of Ants' Communities. Nauka, Moscow, 280 pp. [in Russian, English abstr.].

Received July 1, 2011; revised and accepted October 31, 2011 